\title{
Ensino de Sociologia no Nível Médio: Estudo exploratório baseado em concepções de professores e estudantes da Grande Florianópolis
}

\author{
The Teaching of Sociology in High School: \\ Exploratory Study based on conceptions of teachers and \\ students from Great Florianopolis
}

Ana Carolina Caridá

Mestranda em Sociologia Política (Universidade Federal de Santa Catarina - UFSC)

carolcarida@gmail.com

\begin{abstract}
Resumo
O trabalho buscou analisar em que medida a disciplina de Sociologia cumpre suas potencialidades educativas nas Escolas Públicas de Florianópolis, Palhoça e Antonio Carlos, todas em Santa Catarina, no período que compreende os anos de 2006 a 2009. Foram coletados dados primários (entrevistas, questionários e observação direta) referentes às concepções de professores e estudantes sobre a disciplina. Intento levantar o que pensam os primeiros com relação às particularidades, os desafios e as funções com as quais a sociologia se depara no âmbito escolar, para enfim contrapor tais concepções com o entendimento dos estudantes em contato com esta ciência. A proposta de estudos consiste em desenvolver reflexões que permitam pensar as contribuições e obstáculos da disciplina nas salas de aula atualmente.
\end{abstract}

Palavras-chave: Ensino de Sociologia. Ensino Médio. Escola Pública. Professores. Estudantes.

\begin{abstract}
The aim is to evaluate the measure in which the subject "Sociology", as taught in Public High Schools in three cities in the State of Santa Catarina, Brazil, fulfills it intended educative possibilities. Primary data were collected from interviews, questionnaires and direct observation, covering a period from year 2006 to 2009 , and referred to how teachers and students view the teaching of Sociology in High School. The idea was, first, to perceive how teachers consider the peculiarities, the challenges and the aims of teaching Sociology in High School, and then compare such views with those which prevail among students which had the subject included in their curricular grid. It is expected that reflections arising from this confrontation may provide a better understanding of present classroom difficulties, and may lead to new developments towards a more fruitful interchange between teachers and students.
\end{abstract}

Keywords: Sociology Teaching. High School Teaching. Public Schools. Teachers. Students.

Originais recebidos em: 13/10/2010

Aceito da publicação em: 28/02/2011

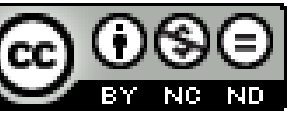

Não-Comercial-Vedada a criação de obras derivadas 3.0 Unported License. 


\section{Introdução}

$\mathrm{O}$ artigo tem o intuito de refletir sobre a finalidade do ensino de sociologia nas escolas de nível médio ${ }^{1}$. O campo de pesquisa analisado compreende os municípios de Florianópolis, Palhoça e Antonio Carlos, todos no Estado de Santa Catarina. Mais especificamente, os objetivos do trabalho foram verificar como os professores de sociologia da rede pública entendem o ensino da disciplina e seu objetivo na escola; identificar o que pensam os alunos sobre as finalidades da disciplina de sociologia na educação escolar; contrapor o entendimento dos professores sobre a disciplina com a compreensão dos estudantes acerca das Ciências Sociais na escola, para enfim analisar em que medida as aulas de sociologia realizam as funções do ensino de Ciências Sociais na escola média.

A sociologia se tornou nacionalmente obrigatória nas escolas de ensino médio em 2008. No Estado de Santa Catarina ela vem sendo lecionada desde 1998, por exigência estadual. Desde então a disciplina está presente no currículo de duas das três séries deste período escolar.

A pesquisa está centrada na análise de dados primários coletados no período de 2006 a 2009. Para realizar este estudo me baseei em oito entrevistas (gravadas e transcritas) concedidas por professores de sociologia da rede pública, estadual e federal, todos formados em Ciências Sociais. Também foram analisados questionários, respondidos pelos estudantes da rede pública, aplicados pelos estagiários do curso de Licenciatura em Ciências Sociais da UFSC, cujos estágios foram realizados entre os anos de 2006 a 2008 (os questionários constam dos relatórios de pesquisa e de estágio supervisionado elaborados para a disciplina de Prática de Ensino em Sociologia). Por fim, a observação direta como fonte de pesquisa também me foi útil, uma vez que tenho freqüentado algumas instituições público-estaduais de ensino desde o primeiro semestre de 2008.

Minha inserção neste campo se deu durante a disciplina de Metodologia do Ensino das Ciências Sociais, onde pude observar pela primeira vez as aulas de sociologia em uma escola estadual. Posteriormente, como estagiária, observei as aulas no Instituto Estadual de Educação (Centro, Florianópolis). Em 2009 comecei a atuar

\footnotetext{
1 Fruto de monografia realizada para a conclusão do curso de bacharelado em ciências sociais na Universidade Federal de Santa Catarina, no ano de 2009.
} 
como professora na E. E. B. Dom Jaime de Barros Câmara (Ribeirão da Ilha, Florianópolis) admitida através de contrato temporário.

São algumas as questões que nortearam este trabalho de pesquisa. São elas: 1) Qual é o espaço destinado ao ensino da sociologia no nível médio neste contexto histórico? 2) Qual é a importância do contato dos estudantes com esta ciência? 3) A sociologia cumpre suas potencialidades educativas na escola? 4) $\mathrm{O}$ que pensam os alunos e professores da disciplina sobre suas funções educativas? 5) Como tem sido transmitido o conhecimento sociológico em sala de aula?

A pesquisa buscou responder a essas questões e desvelar se o ensino de sociologia nas escolas públicas de Florianópolis, Palhoça e Antonio Carlos têm desenvolvido as potencialidades educativas da disciplina ou não.

\section{Da abertura democrática à consolidação da Sociologia no currículo escola}

No período referente à dissolução do regime militar e retorno à democracia foi possível dar início a uma readequação da estrutura educacional brasileira. O intuito naquele momento era o de abolir a profissionalização compulsória, enfatizando a formação geral do ser humano e recomendando a sociologia e a filosofia como parte diversificada do currículo (Lei 7.044/1982). Esta lei fortaleceu a discussão acerca da obrigatoriedade das disciplinas no currículo escolar nos anos finais da ditadura militar (Jinkings, 2007).

Em 1996 é instituída a nova Lei de Diretrizes e Bases da Educação Nacional (Lei ${ }^{\circ}$. 9394/96). Esta lei em seu artigo 36 propõe que ao final do ensino médio todos os alunos tenham conhecimento das disciplinas de filosofia e sociologia, necessários ao exercício da cidadania. Em 1998 é criada em Santa Catarina uma Lei Estadual (LC173/98) que torna a disciplina de sociologia obrigatória para o currículo do ensino médio.

Em 2000 o deputado Padre Roque (PT-PR) apresenta um projeto de lei ao Congresso Nacional. Após projeto ser aprovado o resultado não foi satisfatório, uma vez que o sociólogo Fernando Henrique Cardoso (PSDB) vetou a PLC 9/00.

No ano de 2008 tramita no Congresso Nacional novo projeto de lei na tentativa de reformular o texto da LDB (1996). O projeto é aprovado pelo Senado Federal e no 
dia 02 de junho de 2008, o Presidente da República em exercício, José Alencar (PMDB), sanciona a obrigatoriedade da sociologia e da filosofia a nível nacional. Esta lei levou o Congresso Nacional a alterar o disposto no artigo 36 da Lei de Diretrizes e Bases da Educação Nacional (LDB), Lei nº 9394 de 1996, a qual em seu parágrafo 1º, inciso III afirmava que o ensino de sociologia e filosofia eram necessários ao exercício da cidadania, sem, todavia explicitar sua obrigatoriedade como disciplina escolar.

No Estado de Santa Catarina a disciplina de sociologia é obrigatória há doze anos (LC173/98). Até o ano de 2008 foi ministrada com a carga horária de duas horas/aula por semana em duas das séries do ensino médio. Atualmente ela integra a grade curricular das três séries do ensino médio, seguindo a mesma carga horária nas $1^{\mathrm{a}} \mathrm{s}$ e $2^{\mathrm{a}} \mathrm{s}$ séries (02 horas/aula semanais) e adotando uma carga horária de apenas 1 hora/aula semanal nas $3^{\mathrm{a}} \mathrm{s}$ séries.

É consenso que a política educacional do governo FHC esteve absolutamente subordinada aos movimentos do neoliberalismo em nível mundial. Ao analisar as influências dos princípios neoliberais na educação brasileira, Gentili (2004) afirma que este período elimina a idéia de uma educação integradora, predominante durante a política do Welfare State nas décadas de 1970/80, e dá início a política da empregabilidade, ou seja, a responsabilidade pelo emprego deixa de ser do Estado e passa a ser do indivíduo. Esta política compreende três eixos fundamentais: redução dos encargos patronais, flexibilização trabalhista e formação profissional permanente. Dessa forma o autor acredita que se trata de legitimar um novo senso comum relacionado às questões do trabalho, da educação, do próprio indivíduo e de sua subjetividade. A idéia é criar uma "nova" consciência das classes trabalhadoras com relação a sua atuação social.

Kuenzer (2004) afirma que anteriormente os modelos educacionais eram mais rígidos, pois os trabalhadores eram braços das máquinas e que atualmente o capital flexível exige que o operador saiba coordenar as máquinas, pensando num contexto mais amplo. Coloca que a educação tradicional adestrava os alunos buscando a memorização, pois este era o método útil no interior de uma fábrica, onde os trabalhos são maçantes e o operário costumava passar toda sua jornada realizando movimentos repetitivos. Uma vez que a eletromecânica foi substituída pela microeletrônica passou a ser necessário mais dispêndio de raciocínio por parte do empregado. 
A autora menciona que ambas as relações, trabalhistas e educacionais, são permeadas pelas contradições do mundo do trabalho. Postula que no interior das fábricas, bem como no interior das escolas, existem inúmeras relações que esboçam a contradição existente entre os meios de produção e a força de trabalho. Cita como exemplo as relações de poder, a má qualificação dos profissionais e as condições materiais de operários, professores e estudantes. Relata que muitos trabalhadores estão desempregados ou trabalham informalmente, porém a idéia que se transmite a eles é de que quanto mais houver qualificação, quanto mais competências ele tiver, mais chance terá de participar do mercado (Kuenzer; 2004).

Em sua crítica da reforma educacional do ensino médio durante o governo de Fernando Henrique Cardoso, Kuenzer assinala sua vinculação aos princípios neoliberais e ao modo atual de acumulação de capital. Para a autora, o interesse econômico está em pauta quando se pensa um modelo educacional. Sendo assim é natural que o mesmo processo que vem ocorrendo em âmbito econômico se configure em âmbito educacional (id. ibid.).

\section{Dos clássicos à atualidade}

As discussões referentes à importância do ensino de sociologia na escola secundária brasileira tiveram destaque em 1954, no $1^{\circ}$ Congresso Brasileiro de Sociologia, onde Florestan Fernandes apresenta argumentos favoráveis a sua introdução nos currículos, enfatizando sua relevância no processo formativo dos jovens. Em um primeiro momento o autor se refere à necessidade de abertura do mercado de trabalho para os profissionais licenciados em Ciências Sociais. Faz menção à necessidade de discussão do ensino de sociologia na escola, fazendo uma espécie de "defesa" de sua modalidade de ensino na Educação Básica (Fernandes, 1976).

Mais especificamente, Florestan Fernandes (1976), está preocupado com dois pontos-chaves. Ele discute qual é a posição que o ensino secundário ocupa naquele momento histórico dentro do sistema educacional brasileiro, e, portanto, qual é a "função" do ensino das Ciências Sociais nestas escolas. Para o autor o ensino da sociologia na escola secundária seria a maneira mais construtiva de divulgação dos conhecimentos sociológicos e sua difusão terá importância para o desenvolvimento da própria ciência sociológica. 
A nova sociologia no Brasil estava preocupada em compreender o seu processo histórico em formação e em transformação, afirmando que o ensino secundário não respondia mais às necessidades da sociedade globalizada. Neste sentido entendia a educação como um processo de demora cultural e social, que precisava corresponder às novas necessidades culturais e sociais, e não mais ser um ensino "enciclopédico" e "propedêutico". A educação básica precisa responder às necessidades concretas do ensinamento para o trabalho e também de uma formação geral do ser humano, de maneira sincrônica. Ela precisa ser laica e gratuita para formar uma força de trabalho que se enquadre nos novos moldes produtivos.

Em um segundo momento Florestan Fernandes (1978) aponta que os problemas sociais a serem "resolvidos" são complexos. Segue argumentando que existem quatro problemas sociais que a civilização humana está tendo de enfrentar. Em primeiro lugar estaria a atual forma de organização da família, da propriedade e do Estado. Em segundo lugar os problemas relativos às condições de vida no campo e na cidade derivadas do processo de urbanização. Em terceiro lugar estariam os problemas sociais resultantes dos conflitos internacionais, e por fim a utilização de técnicas baseadas em descobertas científicas, por exemplo, a organização da produção agrícola ou industrial pela tecnologia.

O autor defende que existem "técnicas de manipulação" que alienam a personalidade dos sujeitos, o que faz com que eles se tornem "inocentes" com relação ao meio em que vivem. As "funções" das Ciências Sociais estariam no sentido de libertar os indivíduos da manipulação que sofrem no que se refere à opinião pública e ao universo da propaganda. Ele afirma que quando as sociedades eram estritamente rurais a sabedoria popular dava conta de explicar a realidade dos que ali viviam. Com o advento da industrialização, as sociedades se tornaram modernas e complexas, o que causou uma reviravolta nos padrões e costumes absorvidos anteriormente. Para ele as relações sociais presentes no mundo moderno só podem ser explicadas através das Ciências Sociais, as quais são capazes de analisar os fenômenos da mesma ordem. Uma vez em contato com esta forma de conhecimento a população poderá se libertar das amarras deste "universo alienante" (Fernandes, 1978).

Wright Mills (1972) ressalta que dentro deste modelo alienante, vivido pela população, existe uma incapacidade de utilizar suas próprias consciências devido ao meio institucional ao qual elas estão inseridas, como por exemplo, o emprego, a família, os vizinhos. Desta forma os indivíduos são “encurralados” pelos seus próprios meios. 
Aponta que a imaginação sociológica seria uma espécie de forma mais frutífera de consciência e está relacionada com a necessidade de compreender o cenário histórico dos indivíduos.

O autor afirma que a história do século XX sofre transformações que caminham para a III Guerra Mundial, e é dentro deste contexto histórico que os indivíduos precisam compreender o sentido de sua própria época e de sua própria vida, para se libertarem da sensação de "encurralamento". Neste sentido, o senso-comum possui uma consciência falsa de suas posições sociais. Defende o conceito de imaginação sociológica para expor seus argumentos com relação às necessidades dos homens na contemporaneidade (Mills, 1972).

A imaginação sociológica abre espaço para compreender este cenário histórico, qual é a estrutura desta sociedade moderna e como é formada sua psicologia. Em primeiro lugar trata-se de compreender seu período histórico, sua experiência individual e seu destino (sociedade-biografia-seqüência histórica). A idéia é pensar o específico, considerando a vida social como um todo, conhecer o sentido social e histórico do indivíduo na sociedade e no período vivido por ele. Este seria o sentido cultural das Ciências Sociais (id. ibid).

Para Mills (1972) as Ciências Sociais devem ser o denominador comum de nosso período cultural e neste sentido, a imaginação sociológica, uma qualidade intelectual necessária. O conceito aponta uma orientação para o presente como história, prometendo um entendimento das realidades íntimas ligadas a realidades sociais mais amplas, onde a razão humana desempenha um papel maior nos questionamentos pessoais dos indivíduos. A ciência aqui é vista como um instrumento de conquista para alcançar este denominador comum.

Para Octavio Ianni (1997) a realidade atual está envolta por um processo de mundialização intensa do capital, que ocorre dentro do modelo de Estado Neoliberal, o qual reduz suas políticas sociais, e dá abertura para o setor privado "cuidar" destes assuntos. A época é de globalização, ou seja, abertura de fronteiras entre os países, o que faz com que o grande capital passe a se locomover pelo mundo todo. Ianni está preocupado com os desafios para a sociologia dentro deste contexto e demonstra que é necessário haver novas reflexões relacionadas às especificidades decorrentes deste processo. Neste contexto as Ciências Sociais seriam uma espécie de fundamentação da prática humana, que ao atingir todas as esferas da vida privada, se tornaria uma forma de autoconsciência científica da realidade social. O autor afirma que é necessário pensar 
no mundo social em que vivemos, compreendendo seu lugar no mundo, enquanto indivíduo dentro de seu tempo histórico.

O último documento oficial publicado em nível nacional tratando do ensino em questão, elaborado pelos sociólogos Amaury César Moraes, Elisabeth da Fonseca Guimarães e Nelson Dácio Tomazi, foram as Orientações Curriculares para o Ensino Médio - Ciências Humanas e Suas Tecnologias (Conhecimentos de Sociologia), em 2006 (OCN's; 2006). O documento menciona que o contato com a disciplina é importante por fazer desenvolver habilidades como a "desnaturalização" e o "estranhamento", particulares às Ciências Sociais e, mas especificamente ao ensino da sociologia.

Os autores colocam que a particularidade da sociologia com relação às demais disciplinas que compõem o currículo das ciências humanas, como história e geografia, é o estudo e a análise dos fenômenos sociais, e que para tal é necessário desencadear nos alunos tal "estranhamento" diante destes fenômenos para que eles possam ser problematizados pelas Ciências Sociais.

As OCN's levantam um questionamento sobre a que espécie de "mediação" o conhecimento científico terá de se dispor para alcançar o "mundo" dos jovens. Está colocado em xeque que os alunos do ensino médio se diferenciam dos alunos da graduação, pois, os primeiros não estão interessados em "desenvolver" seu "olhar sociológico", estão cursando o ambiente escolar obrigados, ou pelos pais ou pela própria sociedade, no que se refere a "melhor" colocação no mercado de trabalho. Já os segundos escolheram por livre e espontânea vontade cursar o nível superior de Ciências Sociais. Portanto, os segundos estão muito mais aptos a desenvolver as "habilidades" propostas, enquanto os primeiros podem nunca alcançá-las se não trabalhadas de forma adequada.

Takagi et al. (2007) colocam que os debates e as análises sobre o ensino de sociologia ainda estão em fase embrionária. Consideram que a produção de seu conhecimento ainda é limitada, uma vez que sofre influência de alguns fatores externos. Um destes fatores seria a separação do universo escolar do universo acadêmico. Afirmam que existe uma hierarquia entre o campo acadêmico, científico e escolar e que neste sentido o ensino ocupa uma posição de menos prestígio com relação aos demais. Tanto no que se refere ao estudo científico desta modalidade a nível acadêmico, quanto aos desafios do dia-a-dia escolar. Defendem a idéia de que existe uma separação entre a escola e a universidade. Nas palavras dos autores existe uma falta de consolidação desta 
modalidade de ensino tanto no campo escolar, devido à sua intermitência nos currículos nacionais, quanto no campo acadêmico, quando se trata de um objeto a ser investigado.

Complementando a idéia acima a autora Ileizi Silva (2002) acredita que o desenvolvimento do pensamento sociológico no Brasil depende da obrigatoriedade do ensino da disciplina de sociologia nas escolas brasileiras de nível médio. A necessidade de atrelar o universo acadêmico ao universo escolar está posta. Retoma-se a idéia que estas duas áreas do conhecimento devem estar relacionadas para que o pensamento sociológico se desenvolva no Brasil. Os argumentos se baseiam no fato de que o ensino de sociologia não consegue seu espaço no universo escolar devido às condições materiais de existência a que os professores da rede pública estão submetidos. Defende que se no âmbito acadêmico também não existe esta valorização com relação a este objeto analítico é mais provável que ele não se legitime como conhecimento escolar necessário (Silva, 2002).

A partir da idéias expostas acima podemos perceber que o ensino de sociologia não depende somente dos professores envolvidos com a disciplina. A questão é muito mais abrangente, pois está relacionada à estrutura educacional do ensino público como um todo. Bem como ao relacionamento que a própria universidade tem com o objeto de pesquisa referente ao ensino das Ciências Sociais no campo escolar.

\section{Campo de pesquisa analisado: apontamentos dos professores entrevistados e dos alunos questionados}

Um dado recorrente mencionado pelos profissionais é a falta de identidade própria ou a conquista de um espaço no âmbito escolar. Alguns afirmaram que a disciplina sofre um preconceito dentro do próprio currículo da escola quando comparada às demais disciplinas da grade curricular. Consideram que a sociologia não tem o mesmo peso que matemática e português, por exemplo. Neste sentido alguns "culpam" a falta de identidade própria no que se refere a sua intermitência no currículo da escola média e sua "falta" de historicidade no ambiente escolar. Por outro lado alguns professores afirmam que a sociologia vem conquistando este espaço dentro do ambiente escolar e que ela está no início de seu processo de valorização.

Para estes profissionais, as ciências humanas são mais questionadoras que as demais ciências. A sociologia não traz a resposta pronta para o aluno, esta ciência 
mostra que não existe certo e errado, mas sim perspectivas diferentes. Outra particularidade referente à sociologia seria o fato de que esta disciplina possibilita $o$ estudante a desenvolver a pesquisa social, ainda que de forma incipiente, e possibilita o professor a atuar como sociólogo dentro do ambiente escolar, nas reuniões pedagógicas e conselhos de classe. Para os mesmos trata-se de uma disciplina que trabalha temas do cotidiano que muitas vezes não são discutidos em outras disciplinas e seu intuito é o de abranger todos os aspectos da vida social.

Os desafios enfrentados pelos professores se verificam no enfrentamento das relações diárias estabelecidas entre os professores de sociologia e os demais colegas, onde os primeiros se sentem descriminados perante o grupo social ao qual pertencem. Muitas vezes a disciplina é tratada como Educação Moral e Cívica (EMC) ou Organização Social e Política Brasileira (OSPB) por parte da direção, a qual solicita a abordagem de valores morais, direitos do consumidor, dentre outros conteúdos abordados no período ditatorial.

Cabe enfatizar que os conteúdos a serem trabalhados na disciplina estão elucidados na Proposta Curricular de Santa Catarina (1998), a qual tem como base a pedagogia histórico-crítica (Gasparin, 2007). Os conteúdos a serem discutidos em sala são: "Surgimento do pensamento sociológico", "Estrutura Social", "Infraestrutura e Superestrutura", "A Divisão do trabalho na sociedade de classe", "Classes sociais", "Estado" e "Movimentos Sociais".

De forma geral os professores afirmam que os alunos não têm domínio teórico das outras disciplinas (história, geografia e português, por exemplo) dificultando o desenvolvimento do aprendizado sociológico. Neste sentido se denota uma dificuldade em ensinar uma disciplina complexa, que exige carga de leitura e discernimento intelectual. É enorme o obstáculo dos professores com relação aos alunos uma vez que muitos deles não têm interesse nenhum pela ciência. Os professores de maneira geral acreditam que este é um desafio enfrentado por todas as disciplinas.

Alguns entrevistados citaram que os professores que atuam nas escolas não estão dispostos em atualizar seus conhecimentos, não possuem uma posição crítica com relação aos fenômenos sociais e com grande freqüência atuam em seus próprios meios partindo das mesmas concepções dos alunos.

Os baixos salários também aparecem como obstáculo freqüente em escala estadual. No geral lecionar em mais de uma escola, enfrentar trânsito, ônibus e a falta de entendimento da própria direção e dos docentes com relação à sociologia são desafios 
constantes. A ausência de reconhecimento profissional está interligada à falta de infraestrutura nas escolas estaduais, com salas lotadas, muitas turmas, dificuldade em utilizar os equipamentos áudio visuais, falta de material didático. Configurando falta de estímulo e condições materiais e psicológicas de realizar um bom trabalho.

Para Charlot (2001) ambos os problemas estão relacionados. O fato dos professores sofrerem com a falta de reconhecimento de suas profissões ocorre concomitantemente com a relação que os jovens mantém com o saber na idade escolar. Por um lado os professores não conseguem ministrar suas aulas com qualidade, por outro os jovens não se interessam por aprender (Charlot, 2001).

A partir das debilidades citadas, a proposta dos professores consiste em ensinar a partir das preocupações dos próprios alunos, do que faz sentido para eles, falando a mesma linguagem (por linguagem entende-se a utilização de tecnologias). Tornando-os cidadãos mais conscientes e preparados para atuaram em seus próprios meios.

$\mathrm{O}$ apanhado qualitativo aponta que uma das potencialidades educativas da sociologia seria a de despertar a capacidade crítica para que o aluno possa compreender o mundo social. Isto ocorreria através de uma conscientização política que vise a "não alienação" e leve o educando a se compreender como sujeito histórico atuante. Os professores entrevistados demarcam que os alunos precisam entender que as mudanças que ocorrem na nossa sociedade e que afetam sua vida cotidiana são partes da mudança estrutural mundial, tanto no que se refere à economia quanto às relações entre os indivíduos e seu próprio meio. Para alguns professores a idéia é adquirir o hábito do questionamento a partir dos questionamentos da disciplina, tomando conhecimento de que as coisas não estão dadas, assimilando uma consciência crítica da realidade social.

No que se refere às particularidades da disciplina, aos desafios enfatizados e às "funções" que ela pode vir a desempenhar na escola, percebe-se que de alguma forma os professores fazem menção à teoria de Florestan Fernandes $(1976,1978)$ e Wright Mills (1972), bem como ao proposto pelas Orientações Curriculares Nacionais (OCN's, 2006). Seus discursos estão contemplados pelo enfoque analítico selecionado para a análise da pesquisa.

Para os professores a consolidação da obrigatoriedade do ensino de sociologia a nível nacional reflete uma luta histórica. Possibilita a abertura do mercado de trabalho para os licenciados em Ciências Sociais (como já mencionado em 1954 por Florestan Fernandes). Colocam que a partir da agregação da sociologia e da filosofia no currículo 
todas as disciplinas da matriz curricular passaram a ter a mesma carga horária, o que garantirá seu reconhecimento a médio ou longo prazo.

De modo geral todos acordam tratar-se de um conhecimento útil para a vida das pessoas. Porém surgiram controvérsias quanto ao seu futuro. Uns defendem a posição de que se corre o risco de dogmatizar a sociologia no ensino médio, criando planos de ensino trancados em si mesmos, retirando a autonomia do docente. Outros pensam que não adianta haver obrigatoriedade se não há integração entre as disciplinas.

Quando questionados sobre a importância do Laboratório Interdisciplinar de Ensino de Filosofia e Sociologia (LEFIS - parceria entre Universidade Federal de Santa Catarina e Secretaria Estadual de Educação de Santa Catarina) alguns relataram estar presentes no momento de consolidação do laboratório, entretanto foram obrigados a se distanciar devido à sobrecarga de trabalho. Consideram essencial reunir professores interessados nas discussões, já que não há nenhum sindicato ou associação que defenda os interesses dos docentes de sociologia, além se ser um espaço de troca e aprendizagem. Todos conhecem a biblioteca digital e afirmam consultá-la esporadicamente, entendem a iniciativa como um apoio necessário à elaboração de propostas de ensino e disponibilidade de material didático.

Os alunos afirmaram que com as aulas de sociologia eles se conscientizam sobre o que está acontecendo ao seu redor. Afirmam compreender melhor o processo de desenvolvimento das desigualdades sociais e reconhecem a importância do ensino de sociologia na escola. Relatam que passam a compreender o sistema social em que estão inseridos, entendendo o "porque" de certos acontecimentos sociais. Sabem que a sociologia é o estudo da sociedade e colocam que é importante ver a realidade de hoje e porque esta é a realidade. Tornam-se capazes de formular opiniões e compreendem como a sociedade está organizada e porque nela existem tantos conflitos.

Outros estudantes comentam que a disciplina trabalha fatos antigos e suas conseqüências na atualidade. Para eles esclarece os acontecimentos sociais e um deles afirma que aprende mais na sala de aula do que vivendo no dia-a-dia. Complementando a idéia outro aluno coloca que a disciplina possibilita o entendimento das causas de determinados fenômenos que ocorrem na sociedade e que sem o estudo da sociologia não seriam compreendidos por ele.

Outro contraponto importante a ser mencionado é que muitos dos questionários analisados não continham resposta alguma. Foram selecionados alunos que possuem algum entendimento com relação à sociologia. Não cabe a análise do trabalho a 
quantificação destes dados, mas sim a qualidade dos mesmos. Ou seja, é claro que não são todos os alunos que tem contato com a disciplina que desenvolvem a argumentação esboçada acima, porém a qualidade de seu ensino ou mesmo suas dificuldades não estão sendo levadas em consideração neste momento.

\section{Considerações finais}

A fim de concluir o artigo, contraponho o entendimento dos professores com a compreensão dos estudantes acerca das Ciências Sociais na escola. Considero que os dados coletados apontam para uma defesa do ensino de sociologia quando se leva em conta que os alunos interessados em estudar compreendem seus ensinamentos, fazendo com que a disciplina atinja suas potencialidades educativas. Por outro lado, existem muitos alunos que se mostram distanciados da disciplina, apontando-a apenas como mais uma na grade curricular. Os dados apontam que os professores relatam de modo geral que quando o estudante se mostra atento o contato com a disciplina torna-se produtivo. Podemos perceber que os alunos preocupados em estudar compreendem alguns de seus fundamentos básicos. Por outro lado os entrevistados assinalam a existência de grande falta de perspectiva, por parte dos alunos, com relação à escola em geral. Uma das causas deste fenômeno pode estar no fato de que os estudantes não vêem sentido nas práticas ali propostas, talvez pela escassez de incentivos públicos condizentes as propostas governamentais de inclusão da população que freqüenta estas escolas, ou talvez pelo próprio modelo educacional proposto, vistos pelos jovens como antiquados.

É sabido que as escolas estaduais deixam a desejar tanto no que se refere ao salário dos professores quanto à disponibilidade de material e recursos didáticos essenciais para o melhoramento das aulas, nestes tempos em que muitos estudantes portam seus "mp4's" e "ipods". Os jovens não se interessam por aulas expositivas que incluem apenas o quadro negro e o giz como recursos visuais. Muitas vezes, quando o professor leva material pedagógico audiovisual eles se sentem atraídos, por tratar-se da realidade que eles têm contato diariamente. São jovens que geralmente estão ligados à internet, ao Orkut e ao Msn, e somente através da aproximação da realidade social deles é que se pode entender suas preocupações e lecionar conteúdos com qualidade (Gasparin, 2007). Há que se reconhecer a juventude com a qual se lida na escola, seus 
interesses e necessidades, para poder responder adequadamente às expectativas formativas da disciplina.

Com base nos resultados da investigação realizada, considero que os obstáculos ao fortalecimento da sociologia podem ser elencados em quatro esferas interrelacionadas: 1) Estrutura precária das escolas público-estaduais; 2) Desinteresse dos alunos frente à forma como o conhecimento é transmitido nas escolas - fragmentado, descontextualizado e dissociado das questões do trabalho; 3) Desinteresse dos professores das outras áreas e da própria instituição de ensino pelo conhecimento sociológico; 4) Desinteresse da sociologia científica por este objeto de pesquisa.

Note-se que os problemas mencionados por Florestan Fernandes (1976) com relação à estrutura educacional no país ainda permanecem; passados cinqüenta anos a discussão se centra no mesmo foco: uma educação que não responde às necessidades sociais da ampla maioria da população brasileira. No que se refere ao ensino da sociologia, para que se desenvolvam suas potencialidades educativas é premente que ocorram profundas transformações no sistema educacional do país. Uma vez solucionados os obstáculos mencionados acima é possível que a sociologia cumpra suas potencialidades educativas em nível escolar.

Para encerrar, questiono, será que o lugar da sociologia no sistema educacional brasileiro tem relação com o modelo neoliberal, o qual exige que os trabalhadores tenham uma visão mais totalizante da fábrica e não tão fragmentada como nos modelos curriculares anteriores a este período histórico?

\section{Referências bibliográficas}

BRASIL: Lei de Diretrizes e Bases da Educação Nacional. 1996.

CHARLOT, Bernard. O jovem, a escola e o saber: uma preocupação social no Brasil. In: Os jovens e o saber - perspectivas mundiais. Tradução: Fátima Murad. Editora Artmed. Porto Alegre. 2001. p. 33-50.

FERNANDES, Florestan. Funções das Ciências Sociais no mundo moderno. In:

Educação e Sociedade. Org. PEREIRA, Luiz e FORACCHI, Marialice M. Companhia Editora Nacional. 9a edição. São Paulo. 1978. Florestan Fernandes, Ensaios de Sociologia Geral e Aplicada, Liv. Pioneira Ed. São Paulo, 1960, p. 291-300.

O Ensino de Sociologia na escola secundária brasileira. In: A Sociologia no Brasil. Petrópolis: Vozes, 1976, p. 105-120. 
GASPARIN, João Luiz. Uma didática para a pedagogia histórico-crítica. Editora Autores Associados. Campinas, São Paulo. 2007.

GENTILI, Pablo. Três Teses sobre a Relação Trabalho e Educação em Tempos Neoliberais. In: Capitalismo, Trabalho e Educação. Orgs. José Claudinei Lombardi, Dermeval Saviani e José Luís Sanfelice. Editora Autores Associados. Campinas, São Paulo. 2004. p. 45-59.

IANNI, Octavio. A sociologia numa época de globalismo. In: Org. L. Ferreira Org. $A$ sociologia no horizonte do século XXI. São Paulo: Boitempo, 1997. p. 13-25.

JINKINGS, Nise. Ensino de Sociologia: Particularidades e Desafios Contemporâneos. In: Mediações: Revista de Ciências Sociais. Volume 12, $\mathrm{n}^{\circ}$ 1, Jan-Jun. Universidade Estadual de Londrina, 2007. p. 113-130.

KUENZER, Acácia. Exclusão Includente e Inclusão Excludente - A nova forma de dualidade estrutural que objetiva as novas relações entre Educação e Trabalho. In: Capitalismo, Trabalho e Educação. Orgs. José Claudinei Lombardi, Dermeval Saviani e José Luís Sanfelice. Editora Autores Associados. Campinas, São Paulo. 2004. p. 7795.

MILLS, Wright. A imaginação Sociológica. $3^{\mathrm{a}}$. ed. Tradução de W. Dutra. Rio de Janeiro: Zahar, 1972. Cap.1. p. 9-32.

ORIENTAÇÕES CURRICULARES NACIONAIS PARA O ENSINO MÉDIO.

Conhecimentos de Sociologia. In: Ciências humanas e suas tecnologias/Secretaria de Educação Básica. Autores: Amaury César Moraes, Elisabeth da Fonseca Guimarães \& Nelson Dácio Tomazi. 2006. p. 101-133.

SANTA CATARINA: Dispõe sobre o Sistema Estadual de Educação. Lei Complementar $\mathrm{n}^{\circ} 170.1998$.

SILVA, Ileizi et al. O ensino das Ciências Sociais: mapeamento do debate em periódicos das Ciências Sociais e da educação de 1940 a 2001. In: Congresso Nacional de Sociólogos, 12, 2002. Curitiba Anais. Curitiba, 2001. p. 6.

TAKAGI, Cassiana Tiemi Tedesco \& MORAES, Amaury César. Um olhar sobre o Ensino de Sociologia: Pesquisa e Ensino. In: Mediações: Revista de Ciências Sociais. Volume 12, nº 1, Jan-Jun. Universidade Estadual de Londrina. 2007. 